\title{
Presence of pink sugarcane mealybug (Hemiptera: Pseudococcidae) increases probability of red rot on sugarcane
}

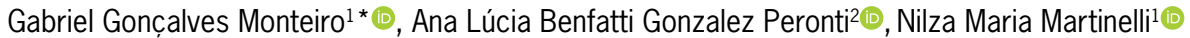

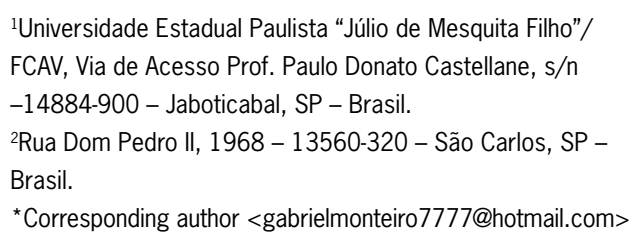

Edited by: Alberto Soares Corrêa

Received November 22, 2020

Accepted February 19, 2021

\begin{abstract}
Saccharicoccus sacchari (Cockerell, 1895) (Hemiptera: Pseudococcidae) is globally disseminated on sugarcane plants. In Brazil, this species has been occurred in the same region as the occurrence of the fungal pathogen causing red rot, Colletotrichum falcatum Went, 1893 (Glomerellales). The objective of this study was to evaluate the hypothesis that this pseudococcid could act as a facilitator of the penetration of the phytopathogen $C$. falcatum. Species of this mealybug were reared at laboratory to infest sugarcane plants during the experiment. A total of 320 sugarcane plants were utilized for this study, 160 of CTC4 and 160 of RB86 7515 cultivars (cv.), each group subdivided into four treatments: (1) infested with mealybugs; (2) infected with fungal conidia; (3) infested with mealybugs and infected with fungal conidia; and (4) control. Biometrics of the plants, disease symptoms, Total Reducing Sugars (TRS) and Reducing Sugar (RS) were evaluated. To both cv., there was no difference in the height and diameter of the plants in all treatments; and only in "mealybug + fungus", significant difference on the lengths of the disease lesions inside the plants was found to each cv. as well as the levels of TRS and RS. The presence of the pseudococcid increased the incidence of the disease in both cv., although RB86 7515 was more susceptible to red rot than CTC4.
\end{abstract}

Keywords: Colletotrichum falcatum, Saccharicoccus sacchari, cultivars, insect, interaction

\section{Introduction}

The pink sugarcane mealybug (PSMB), Saccharicoccus sacchari (Cockerell, 1895) (Hemiptera: Pseudococcidae) occurs in all the zoogeographic regions except Antarctica, having been reported in every sugarcane crop around the world (García et al., 2017).

In Brazil, the fungus of the red rot (FRRD), caused by Colletotrichum falcatum Went, 1893 (Glomerellales) on sugarcane had been registered in the same regions, as the high infestation of this mealybug (Sharma and Tamta, 2015; García et al., 2017).

The mealybug initially infests newly-planted sugarcane rhizomes, up to $30 \mathrm{~cm}$ of depth; and later, as the plant grows, it forms colonies on the region of the sugarcane nodes under the leaf sheaths (Tohamy et al., 2008). Within a crop and in short distance dispersal the nymphs are mainly transported to nearby plants by ants and the movements of the air provided by jet-transported equipment (Tohamy et al., 2008). Infested plants left after harvest favor the reinfestation of this insect to the next crop cycle (Beardsley, 1962). Puttarydriah (1954) registered plant growth retardation and death of the young sugarcane shoots caused by the PSMB. Reduction of diameter and weight of the stems and reduction of sugars of $13 \%$ were also confirmed (Kalra and Sidhu, 1964; Atiqui and Murad, 1992; Gamal El-Dein et al., 2009). The insect is also a vector of the sugarcane bacilliform virus (SCBV) (Victoria et al., 2005).

Colletotrichum falcatum is an agent of the red rot (Abbas et al., 2010; Sharma and Tamta, 2015). This fungus reduces up to $33 \%$ in sucrose extraction, $40 \%$ loss of sugar and alcohol, and $41 \%$ of Reducing Sugar
(RS), measurement of glucose and fructose (Viswanathan and Rao, 2011). It is responsible for the inversion of the sucrose, transforming into glucose and fructose, which generates the non-crystallization of the sugar during the industrial process.

The modes of infection of conidia of $C$. falcatum are mainly perpetuated by infected plants, diseased stubble and when they are left in the soil (Sharma and Tamta, 2015). Secondary transmission of the fungus is mediated by rain water, rain splash, air currents, infecting through the nodes, and also borers insects, especially during germination and establishment phase (Bulhões et al., 2012; Sharma and Tamta, 2015).

The objective of this work was to evaluate the hypothesis that $S$. sacchari can act as a secondary transmitter for the penetration of the $C$. falcatum conidia.

\section{Materials and Methods}

The experiment was conducted between Apr 2017/2018, in the municipality of Jaboticabal, state of São Paulo, Brazil. The mealybugs were reared at laboratory, also the conidial suspensions of the fungus; the plants were cultivated in a greenhouse with temperature ranging from 28 to $30{ }^{\circ} \mathrm{C}$; and the technological analysis was done in Ribeirão Preto, state of São Paulo, Brazil.

\section{Buds planting}

A total of 640 buds were planted: 320 of the cultivar (cv.) CTC4, originating from the Sugarcane Technology Center (CTC), and 320 of the cv. RB86 7515 from the Inter-University Network for the Development of the 
Sugar-Energy Sector (RIDESA). These cv. correspond to those most used in the state of São Paulo (Ripoli and Ripoli, 2004).

Two buds per pot were planted at five $\mathrm{cm}$ of depth and five $\mathrm{cm}$ apart from each other, in Apr 2017. The plastic pots of $34 \mathrm{~cm}$ of diameter with capacity of eight $\mathrm{L}$ were previously prepared with a ratio of 3:1:1 (soil, sand and organic matter). After planting, NPK fertilizer 4-1638 (300 mg of Nitrogen, $200 \mathrm{mg}$ of Phosphorus and 150 mg of Potassium) was added to each L of soil. The plants were watered daily during all the experiment.

When the plants reached the tillering phase, two months after planting, only one plant was kept in each pot. The removed plants were transplanted to pots in which germination had not occurred. In addition, a bamboo stake was included in each pot to support the plants. When the plants reached the grand growth period, 90 days after the planting, the original pots were positioned into randomized design into four treatments to each cv.; "mealybug", "fungus", "fungus + mealybug" and "control".

\section{Rearing of Saccharicoccus sacchari}

Fifteen plants of the cv. RB86 7515 were selected and collected from a properties located in the municipality of Jaboticabal, São Paulo $\left(21^{\circ} 13.227^{\prime}\right.$ S, $48^{\circ} 16.819^{\prime}$ $\mathrm{W}$, altitude of $605 \mathrm{~m}$ ), intended for the rearing of the mealybugs.

At the laboratory, the leaves were removed and the stem of the plants was segmented into six buds. These were washed by running water, then they were sterilized with $70 \%$ alcohol and dried through disposable rags, finally they were exposed until completely dried.

The ends of the stems were dipped into liquid paraffin, and they were immediately inserted into a container of cold water. This procedure was repeated until a complete seal was obtained at the ends of the stems, as described by Beardsley (1962). A total of 18 PET bottles, without their ends, served as a horizontal support to five parafined cut stems.

Approximately 180 specimens of ovipositing females of $S$. sacchari were acquired in the localities previously mentioned.

Each cut stem was infested with two mealybugs, each inserted on the base of the leaf sheaths. The parafined stems for rearing, accommodated into the PET bottles, were kept horizontally in BOD Incubator (Bio-Oxygen Demand), with temperature of $25 \pm 2{ }^{\circ} \mathrm{C}$, photoperiod $00 \mathrm{~h} 24$ (light and dark), and humidity of $80 \%$.

\section{Conidial suspensions of the fungus Colletotrichum falcatum}

Colletotrichum falcatum was obtained by means of inoculum taken from the stems with red rot symptoms, in a rural property of the municipality of Jaboticabal, $\left(21^{\circ} 17.315^{\prime} \mathrm{S}, 48^{\circ} 18.636^{\prime} \mathrm{W}\right.$, altitude of $\left.605 \mathrm{~m}\right)$. Symptoms observed to detect diseased plants were discoloration of the stalks orange to yellow, gradually dry of the leaves, elongated white spots in the pith of the leaves, reddish-brown color in the affected node and rusty-brown appearance on the leaves (Prihastuti et al., 2010; Sen et al., 2015; Viswanathan and Rao, 2011). After the confirmation of the fungus species, tissue segments with the disease symptoms were cut and treated. The segments were placed in alcohol and then in sodium hypochlorite solution and water. Posteriorly, the conidia were placed in the PDA (Potato, Destroxe, Agar) culture medium, and then it rested for 15 days to ensure its growth. After purification and multiplication of the fungus in Petri dish, a suspension was obtained with a concentration of $10^{5}$ conidia $\mathrm{mL}^{-1}$ by counting them at Neubauer chamber (Araújo and Stadnik, 2013).

\section{Infestation of Saccharicoccus sacchari and infection of Colletotrichum falcatum}

When the plants reached approximately $1.70 \mathrm{~m}$ (final phase of tillering), the treatments "mealybug" and "mealybug + fungus", of the cv. CTC4 and RB86 7515 were infested with a total of 1600 specimens of adult females, obtained from the mealybug rearing, ten specimens per plant, five ovipositing females on the median region and five on the upper region.

The establishment occurred when first and second instars nymphs were observed on the nodes of the plants in Jan 2018, descended from the ovipositing females. The pathogen infection in the plants of the treatments "fungus" and "mealybug + fungus" was carried out during this period by applying the $10^{5}$ conidia $\mathrm{mL}^{1}$ suspension, with the aid of a dropper, on the sheath of the plants, near to the initial placed pseudococcids, placing 2 $\mathrm{mL}$ per stem, which was adequate concentration for the disease infection (Abbas et al., 2010). The sporulation of the fungus under greenhouse conditions was guaranteed by the maintenance of humidity of $80 \%$ to the plants, for a period of $24 \mathrm{~h}$, provided by water mister (Franco et al., 2014).

\section{Biometry and evaluation of the lesions in sugarcane plants}

After the inoculation and the establishment of the mealybugs and the fungus in the two cv., during the ripening phase, the plants were evaluated. For the measurement of their stem height was used a measuring tape, and to determine the stem diameter was used a caliper at the bottom of the plant. When the plants exhibited external symptoms of the disease, during the same period, the stems were vertically opened using a machete, and the presence of disease lesions was analyzed. The reddish spots were measured by a ruler, obtaining measurements of their length. 


\section{Technological analysis}

Technological analysis; Total Reducing Sugars (TRS) measurement of sucrose and Reducing Sugar (RS) glucose and fructose, and Reducing Sugar (RS) measurement of glucose and fructose, of the plants, were done according to proposed by Lane and Eynon (Ripoli and Ripoli, 2004).

After the biometry of the plants and the evaluation of the lesion, the homogenized sample was weighted. To determine Total Reducing Sugars (TRS) distilled water was added for dissolution of the sample, then concentrated hydrochloric acid was added and placed in a water bath. This solution was cooled and neutralized with sodium hydroxide and used $\mathrm{pH}$ indicator paper. To determine Reducing Sugar (RS) potassium ferrocyanide and zinc acetate was added, and the sample was flocculated and sediment, filtered and put into the burette, and volumetrically pipetted. Finally, there was added to the material distilled water, warmed to boiling and added methylene blue.

\section{Experimental design and statistical procedures}

The experimental design used was completely randomized design (CRD) with four treatments and 40 replicates to each cv. The program used was $\mathrm{SAS}^{\circledR}$ University Edition, version 9.4 . The data, height and diameter of the plants, and length of the disease inside the sugarcane were submitted to Bartlett's tests to verify homocedasticity (PROC GLM) and Cramer von Mises's test for normality (PROC UNIVARIATE). The data showed normality in this way the Analysis of Variance (PROC ANOVA) was conducted. The means (PROC MEANS) when significant were compared using the Tukey test $(p<0.05)$ (Everitt and Hothorn, 2005).

\section{Results}

\section{Biometric of the plants and the disease}

To both cv., there was no significance difference in the height $(\mathrm{m})$ and diameter $(\mathrm{mm})$ of the plants in all treatments. However, only in treatment "fungus + mealybug" significant difference on the lengths of the disease lesions inside the plants was observed for both cv. The cv. CTC4, on this treatment, presented 3.7 $\pm 0.59 \mathrm{~cm}$ of lesion, and the cv. RB86 7515, on this treatment, presented higher measures, with $7.1 \pm 0.92$ $\mathrm{cm}$ of lesion. Also, in both cv., treatments "mealybug", and "control" did not present disease lesion inside the plants (Tables 1 and 2).

\section{Technological parameters}

The Total Reducing Sugars (TRS) of both cv. presented significant difference on the treatments "mealybug", "fungus" to the treatments "mealybug + fungus" and
Table 1 - Sugarcane plants height $(\mathrm{m})$ and diameter $(\mathrm{mm})$, and disease length $(\mathrm{cm})$ inside the plant, on the different treatments after inoculation and infestation of the fungus and the mealybugs to the cv. CTC4.

\begin{tabular}{lccc}
\hline Treatments & Plants ht & Plants diam & Disease lgth \\
\hline & $\mathrm{m}$ & $\mathrm{mm}$ & $\mathrm{cm}$ \\
Mealybug & $2.1 \pm 0.07 \mathrm{a}^{*}$ & $17.5 \pm 0.45 \mathrm{a}^{*}$ & $0.0 \pm 0.00 \mathrm{~b}^{*}$ \\
Fungus & $2.2 \pm 0.05 \mathrm{a}$ & $17.7 \pm 0.33 \mathrm{a}$ & $0.9 \pm 0.31 \mathrm{~b}$ \\
Mealybug + Fungus & $2.2 \pm 0.04 \mathrm{a}$ & $18.3 \pm 0.45 \mathrm{a}$ & $3.7 \pm 0.59 \mathrm{a}$ \\
Control & $2.2 \pm 0.07 \mathrm{a}$ & $17.5 \pm 0.61 \mathrm{a}$ & $0.0 \pm 0.0 \mathrm{~b}$ \\
\hline
\end{tabular}

${ }^{*}$ Means \pm standard error followed by the same letter in the same column do not differ by Tukey test $(p>0.05)$; Plants height $(\mathrm{m})(\mathrm{F}=4.04 ; \mathrm{df}=3 ; p$ $<.0001$ ), plants diameter $(\mathrm{mm})(\mathrm{F}=0.69 ; \mathrm{df}=3 ; p<0.1940)$, length of the disease $(F=8.92 ; d f=3 ; p<.0001)$.

Table 2 - Sugarcane plants height $(\mathrm{m})$ and diameter $(\mathrm{mm})$, and disease length $(\mathrm{cm})$ inside the plant, on the different treatments after inoculation and infestation of the fungus and the mealybugs to the cv. RB86 7515.

\begin{tabular}{lccc}
\hline Treatments & Plants ht & Plants diam & Disease lgth \\
\hline & $\mathrm{m}$ & $\mathrm{mm}$ & $\mathrm{cm}$ \\
Mealybug & $1.7 \pm 0.10 \mathrm{a}^{*}$ & $17.7 \pm 0.76 \mathrm{a}^{*}$ & $0.0 \pm 0.00 \mathrm{~b}^{*}$ \\
Fungus & $1.9 \pm 0.08 \mathrm{a}$ & $19.0 \pm 0.55 \mathrm{a}$ & $1.2 \pm 0.71 \mathrm{~b}$ \\
Mealybug + Fungus & $1.8 \pm 0.08 \mathrm{a}$ & $18.8 \pm 0.63 \mathrm{a}$ & $7.1 \pm 0.92 \mathrm{a}$ \\
Control & $1.9 \pm 0.06 \mathrm{a}$ & $18.9 \pm 0.43 \mathrm{a}$ & $0.0 \pm 0.00 \mathrm{~b}$ \\
\hline
\end{tabular}

*Means \pm standard error followed by the same letter in the same column do not differ by Tukey test $(p>0.05)$; Plants height $(\mathrm{m})(\mathrm{F}=3.38$; $\mathrm{df}=3 ; p$ $<.0001)$, plants diameter $(\mathrm{mm})(\mathrm{F}=0.73 ; \mathrm{df}=3 ; p<0.1940)$, length of the disease $(\mathrm{F}=16.10 ; \mathrm{df}=3 ; p<.0001)$.

"control". On the other hand, all treatments related to both cv. presented significant difference to Reducing Sugar (RS). The treatments "mealybug" presented $5.8 \%$ TRS and $1.6 \%$ RS for CTC4, and $8.3 \%$ TRS and $1.1 \%$ RS for RB86 7515 cv. (Table 3).

\section{Discussion}

During the ripening phase the analysis of the treatments showed: (1) lower plants for both cv. to the treatments "mealybug"; (2) greater incidence of the disease lesions inside the plants of the treatments "fungus + mealybug" for both cv.; and, (3) lower levels of Total Reducing Sugars (TRS) to cv. CTC4, and Reducing Sugar (RS) to RB86 7515, however, presenting the lowest (TRS) values to the "mealybug" treatments of both cv.

The temperature for conducting the experiment, 28 to $30{ }^{\circ} \mathrm{C}$, it was similar to that proposed by Patel and Krishnamurthy (2017) for a well success development of the mealybugs. In India, they observed that this temperature in the greenhouse provided the best development and growth of the fungus in sugarcane plants, since the pathogen disperses faster in this condition. However, the low incidence of the disease observed in the treatments, apart from "mealybug + fungus" for both cv., probably occurred due to the 
Table 3 - Technological parameters, Total Reducing Sugar (TRS) measurement of sucrose and Reducing Sugar, glucose and fructose (\%) and Reducing Sugar (RS) measurement of glucose and fructose (\%) on the different treatments after inoculation and infestation of the fungus and the mealybugs to both $\mathrm{cv}$.

\begin{tabular}{|c|c|c|c|c|}
\hline \multirow{2}{*}{ Treatments } & \multicolumn{2}{|c|}{ cv. CTC4 } & \multicolumn{2}{|c|}{ cv. RB86 7515} \\
\hline & TRS & RS & TRS & RS \\
\hline & & & 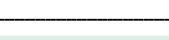 & - \\
\hline Mealybug & $5.8 \pm 1.41 c^{*}$ & $1.69 \pm 0.00 a^{*}$ & $8.3 \pm 1.25 c^{*}$ & $1.19 \pm 0.00 a^{*}$ \\
\hline Fungus & $6.2 \pm 1.63 b$ & $1.65 \pm 0.00 c$ & $9.0 \pm 1.63 b$ & $1.05 \pm 0.00 \mathrm{~b}$ \\
\hline Mealybug + Fungus & $6.6 \pm 1.63 \mathrm{a}$ & $1.67 \pm 0.00 b$ & $9.6 \pm 1.63 \mathrm{a}$ & $1.00 \pm 0.00 c$ \\
\hline Control & $6.7 \pm 1.63 \mathrm{a}$ & $1.63 \pm 0.00 \mathrm{~d}$ & $9.7 \pm 1.63 \mathrm{a}$ & $0.95 \pm 0.00 \mathrm{~d}$ \\
\hline
\end{tabular}

* Means \pm standard error followed by the same letter in the same column do not differ by Tukey test $(p>0.05)$; cv. CTC4 TRS (kg t) ( F $=24.41 ; \mathrm{df}=3 ; p<.0001)$, cv. CTC4 RS (\%) (F = 40.00; df = 3; $p<.0001)$, cv. RB86 7515 TRS (kg t) $(F=65.56 ; d f=3 ; p<.0001)$, cv. RB86 7515 RS $(\%)(F=641.50 ; d f=3 ; p<.0001)$.

concentration of the suspension of $10^{-5}$ conidia $\mathrm{mL}^{-1}$, and/or the number of these applications were low. According to Lins et al. (2007) the application of the suspension of $10^{-6}$ conidia provided the inoculation and development of several isolates of Colletotrichum spp. causing diseases in different $\mathrm{cv}$. of coffee plants.

However, among the plants with symptoms of the disease, those of the treatment "mealybug + fungus" were those that presented the most extensive lesions, with differences to both cv., and RB86 7515 presenting the highest one. The presence of the scale insect in relation to its sucking alimentary habit became an indicative in providing openings on the plants for inoculation of the spores of the fungus. These insects have sucking mouthpiece with four adapted stylets (Leopold et al., 2003). Although the size of the holes resulted from the bites for introduction of the stylets are unknown for this species, the diameter of the rostrum and stylets is known to some pseudococcids such as the grape mealybug, Phenacoccus aceris (Sinoret, 1875) (Hemiptera: Pseudococcidae), which may range from 0.71 to $3 \mu \mathrm{m}$ in diameter (Alliaume et al., 2018). Considering that the openings may have equal or greater diameter of the stylets of these insects, and that the conidia of Colletotrichum spp. have smaller biometric parameters, average $11.2 \mu \mathrm{m}$ in length and $4.5 \mu \mathrm{m}$ in diameter (Lins et al., 2007), it is assumed that the penetration of the spores through the numerous perforations caused by the bites of the scale insects around the nodes would be viable. In addition, in the rainy season, the incidence of the disease would be higher, because the accumulation of water near these perforations can be a facilitator for fungal sporulation (Bulhões et al., 2012).

Evaluation of the biometric and technological analyzes showed that the sugarcane plants of cv. CTC4 was higher in height than the cv. RB86 7515, also higher values of Reducing Sugar (RS), and RB86 7515 presenting higher values of Total Reducing Sugars (TRS). According to Ripoli and Ripoli (2004) these characteristics are inherent to the biotype of the two cv. The technological data obtained on the presence or absence of mealybug and the fungus, together or separately, may be not determinant factors to the physicochemical characteristics of both cv., but the treatments "mealybug" indicate that the presence of the insect may reduce the values of TRS, which is the sum of Reducing Sugar (RS) with sucrose converted in Reducing Sugar (RS), also the height of the plants, and increase the values of RS, which are glucose and fructose (Ripoli and Ripoli, 2004).

A similar result was observed in India, where the presence of $S$. sacchari caused TRS reduction of $21 \%$ (Atiqui and Murad, 1992; Gamal El-Dein et al., 2009), and the presence of the fungus reduced the TRS by up to $50 \%$ (Franco et al., 2014; Ripoli and Ripoli, 2004).

Disease symptoms were more frequent in plants of the treatments "mealybug + fungus" for both cv., which the mealybugs are facilitating the penetration of the $C$. falcatum conidia in plants of Saccharum spp. Although, there was recorded the disease in low incidence, in treatments "fungus", which may be associated to natural openings of the plants.

Regarding general levels of Total Reducing Sugars (TRS) should be between 13 to $15 \%$ and levels of Reducing Sugar (RS) less than $0.8 \%$ (Ripoli and Ripoli, 2004), none of the treatments for both $\mathrm{cv}$. reached TRS and RS suggested parameters, but the treatment "mealybug" for both cv. was the one that decreased most these levels. In addition, the cv. RB86 7515 showed more susceptible of this disease than CTC4 by presenting higher disease length inside the plant. The replication of this study with another susceptible cv. of sugarcane to the involved agents, will contribute to support the given hypothesis.

\section{Acknowledgments}

This study was financed in part by the Coordination for the Improvement of Higher Level Personnel (CAPES) Finance Code 001.

\section{Authors' Contributions}

Conceptualization: Monteiro, G.G.; Peronti, A.L.B.G.P.; Martinelli, N.M. Data acquisition: Monteiro, G.G. Data analysis: Monteiro, G.G. Design of methodology: Monteiro, G.G.; Peronti, A.L.B.G.P.; Martinelli, N.M. Software development: Monteiro, G.G. Writing and editing: Monteiro, G.G.; Peronti, A.L.B.G.P.; Martinelli, N.M. 


\section{References}

Abbas, H.; Anwar, S.A.; Javed, N.; Iqbal, M.A. 2010. Morphological variability among isolates of Colletotrichum falcatum Went: infecting four cultivars of sugarcane. Pakistan Journal of Phytopathology 22: 101-104.

Alliaume, A.; Reinbold, C.; Uzest, M.; Lemaire, O. 2018. Mouthparts morphology of the mealybug Phenacoccus aceris. Bulletin of Insectology 71: 1-9.

Araújo, L.; Stadnik, M.J. 2013. Cultivar specific and ulvan induced resistance of apple plants to Glomerella leaf spot are associated to an enhanced activity of peroxidases. Acta Scientiarum 35: 1-7. https://doi.org/10.4025/actasciagron.v35i3.16174

Atiqui, M.U.A.; Murad, H. 1992. Assessment of loss in sucrose content of sugarcane due to sugarcane mealy bug, Saccharicoccus sacchari Ckll. Journal of Insect Science 5: 196197.

Beardsley, J.W. 1962. Notes on the biology of the pink sugar cane mealybug, Saccaricoccus sacchari (Cockerell), in Hawaii (Homoptera: Pseudococcidae). Proceedings of the Hawaiian Entomological Society 18: 55-59.

Bulhões, C.C.; Bonaldo, S.M.; Teodósio dos Santos, B.; Trento, R.A. 2012. Alternative products to control anthracnose (Colletotrichum gloeosporioides), cladosporiosis (Cladosporium herbarum) and bacteriosis (Xanthomonas campestris $p v$. passiflorae) in passion fruit in northern Mato Grosso. Revista Ciências Exatas e da Terra e Ciências Agrárias 7: 12-19 (in Portuguese, with abstract in English).

Everitt, B.S.; Hothorn, T. 2005. A Handbook of Statistical Analyses Using R. Technometrics, London, UK.

Franco, F.P.; Santiago, A.C.; Henrique-Silva, F.D.C.; Pa, G.G.H. 2014. The Sugarcane defense protein SUGARWIN2 causes cell death in Colletotrichum falcatum but not in non-pathogenic fungi. PLoS One 9: e91159. https://doi.org/10.1371/journal. pone.0091159

Gamal El-Dein, H.; Mohamed Sanaa, A.; Ibrahim, M.; Fatma, A.M. 2009. Effect of Saccharicoccus sacchari (Cockerell) infestation levels on sugarcane physical and chemical properties. Egyptian Academic Journal of Biological Science 2: 119-123.

García, M.M.; Denno, B.D.; Miller, D.R.; Miller, G.L.; BenDov, Y.; Hardy, N.B. 2017. ScaleNet: a literature-based model of scale insect biology and systematics. Available at: http:// scalenet.info [Accessed Apr 19, 2018]
Kalra, A.N.; Sidhu, A.S. 1964. Sugarcane mealybug, Saccharicoccus sacchari Ckll., and its control. Proceedings of the Indian Academy of Science 5: 557-559.

Leopold, R.A.; Freemanb, T.P.; Bucknera, J.S.; Nelsona, D.N. 2003. Mouthpart morphology and stylet penetration of host plants by the glasswinged sharpshooter, Homalodisca coagulata, (Homoptera: Cicadellidae). Arthropod Structure \& Development 32: 189-199.

Lins, S.R.O.; Alves, E.; Abreu, M.S. 2007. Histopathologic study of Colletotrichum spp. in coffee plantlets. Fitopatologia Brasileira 32: 488-495 (in Portuguese, with abstract in English).

Patel, P.; Krishnamurthy, R. 2017. Physiological profiling of Colletotrichum falcatum, the causal agent of Sugarcane Red rot disease. Journal of Mycopathologial Research 55: 269-274.

Prihastuti, H.; Cai, L.; Crouch, J.A.; Phoulivong, S.; Moslem, M.A.; McKenzie, E.H.C.; Hyde, K.D. 2010. Neotypification of Colletotrichum falcatum, the causative agent of red-rot disease in sugarcane. Sydowia-Horn 1: 283-293.

Puttarydriah, M. 1954. The status of the mealy-bug on sugarcane with special reference to Mysore State. Indian Journal of Entomology 16: 1-10.

Ripoli, T.C.C.; Ripoli, M.L.C. 2004. Sugarcane biomass: harvest, energy and environment = Biomassa de cana-de-açúcar: colheita, energia e ambiente. Barros \& Marques, Piracicaba, SP, Brazil (in Portuguese).

Sharma, R.; Tamta, S. 2015. A review on red rot: the "cancer" of sugarcane. Journal of Plant Pathology and Microbiology 8: 1-8. https://doi.org/10.4172/2157-7471.S1-003

Tohamy, T.H.; El-Raheem, A.A.A.; El-Rawy, A.M. 2008. Role of the cultural practices and natural enemies for suppressing infestation of the pink sugarcane mealybug: Saccharicoccus sacchari (Cockerell) (Hemiptera: Pseudococcidae) in sugarcane fields at Minia Govemorate, Middle Egypt. Egyptian Journal of Biological Pest Control 18: 177-188.

Victoria, J.I.; Avellaneda, M.C.; Angel, J.C.; Guzmán, M.L. 2005. Resistance to Sugarcane yellow leaf virus in Colombia. International Society of Sugar Cane Technologists 25: 664-670.

Viswanathan, R.; Rao, G.P. 2011. Disease scenario and management of major sugarcane diseases in India. Sugar Tech 13: 336-353. https://doi.org/10.1007/s12355-011-0102-4 